\title{
Globalización y diversidad sexual, gays y mariquitas en Andalucía
}

Globalization and sexual diversity, gays and mariquitas in Andalusia

\author{
Rafael Cáceres Feria \\ Universidad Pablo de Olavide. Sevilla (España) \\ rcacfer@upo.es
}

\section{José María Valcuende del Río}

Universidad Pablo de Olavide (Sevilla). Investigador invitado de la Universidad de Cuenca (Ecuador). Proyecto Prometeo (SENECYT).

jmvalrio@upo.es

\author{
CUERPOS, SEXUALIDADES Y PODER \\ MONOGRÁFICO COORDINADO POR JOSÉ MARÍA VALCUENDE. Universidad Pablo de Olavide (Sevilla).
}

\begin{abstract}
RESUMEN
La globalización en el ámbito de la sexualidad ha provocado procesos de expansión de determinados modelos de homosexualidad masculina. A partir de las investigaciones que hemos realizado en Andalucía (España), pretendemos cuestionar la uniformidad del modelo gay, como el inevitable final de un recorrido histórico que llevará a la homogeneización de las identidades sexuales. Realizaremos una revisión de la literatura científica al respecto, para centrarnos posteriormente en el modelo social construido en torno al hombre afeminado andaluz.
\end{abstract}

\section{ABSTRAC T}

Globalization in the field of sexuality has caused processes of expansion in certain models of male homosexuality. Beginning with our research in Andalusia (Spain), we seek to question the uniformity of the gay model as the inevitable end of a historic journey that will lead to a homogenization of sexual identities. We first review the scientific literature on this subject, and afterwards we focus on the social model built regarding the effeminate Andalusian man.

PALABRAS CLAVE

mariquita | Andalucía | homosexualidad | identidad | sexualidad | género

KEYWO RDS

mariquita | Andalusia | homosexuality | identity | sexuality | gender

\section{Introducción}

Este trabajo (1) parte de un proceso de reflexión personal de los autores que evidenciaron, a través de su experiencia vital, las marcadas diferencias en las formas de vivir y visibilizar la homosexualidad en los diferentes lugares de España donde habitaron, en un periodo en que convivían las formas "tradicionales" de entender la sexualidad con modelos emergentes, que se generalizan a partir del proceso de democratización del país y que han sido analizados ampliamente en la literatura científica española (Guasch 1991, Mira 2004, Villaamil 2004). Mientras en el caso andaluz, determinadas formas de entender la homosexualidad se hacían visibles socialmente, tal y como veremos posteriormente, no ocurría lo mismo en las zonas rurales castellanas o vascas, por ejemplo. A partir de esta experiencia, comenzamos a trabajar académicamente en el análisis de los modelos sociales en torno a la sexualidad en Andalucía durante los últimos años de la década de los noventa del siglo XX (2). Desde entonces y hasta hoy, hemos ido recopilando información etnográfica y entrevistas a partir de las que abordamos algunas de las cuestiones centrales que guían este texto, que plantea el proceso de hibridación de la homosexualidad en Andalucía, un aspecto apenas tratado en la Antropología española. Durante este tiempo hemos llevado a cabo observación en diferentes ámbitos de sociabilidad homosexual $y$, también, en contextos festivos ceremoniales (romerías, fiestas patronales, cruces de mayo, semana santa, corpus...), realizando entrevistas en profundidad y recogiendo cuantiosa información a través de conversaciones informales. Nuestro trabajo de campo se ha centrado especialmente en la zona occidental de Andalucía, en las provincias de Huelva, Sevilla, Cádiz y Málaga; tanto en las capitales de provincia como en poblaciones de 
muy diverso tamaño. Otra fuente utilizada, que nos ha permitido acceder a información de toda Andalucía, incluida la zona oriental, han sido los foros de internet centrados en la Semana Santa, donde la presencia de "homosexuales" es muy alta.

Partimos precisamente de la singularidad del modelo andaluz, lo que nos lleva a cuestionar, tal y como han hecho otros autores, el carácter homogéneo de la homosexualidad occidental en general, y de la homosexualidad en España, en particular, sin que por ello neguemos la existencia de elementos compartidos. Este hecho nos lleva a preguntarnos sobre el proceso de globalización de la homosexualidad, denominación que encierra bajo un mismo término una pluralidad de realidades diferentes, lo que nos obliga también a repensar la articulación entre los fenómenos globales y los fenómenos locales, en concreto, en el caso andaluz.

\section{2. ¿Sexualidades globales versus sexualidades locales?}

La globalización se ha representado en el imaginario social como un proceso tendente a la eliminación de la diversidad cultural. El debate en torno a su carácter homogeneizador se ha convertido en uno de los ejes centrales de las discusiones académicas: ¿Hasta qué punto la globalización destruye las culturas e impone pautas de conducta en todo el planeta? Son muchos los que defienden que la globalización se ha convertido en una devoradora de las diferencias culturales y que estamos abocados a una única cultura mundial. Desde esta perspectiva, globalización se equipara a americanización o mcdonalización. Frente a esta visión distópica surgen voces que defienden que, aun siendo innegable su capacidad de homogeneizar hábitos y pensamientos, el análisis de la realidad nos permite entrever que sus efectos son mucho más complejos. No es un fenómeno unilineal. "El problema central de las interacciones globales en la actualidad es la tensión entre la homogeneización y la heterogeneización cultural" (Appadurai 2001: 30). Efectivamente, junto al proceso uniformador se aprecian tendencias a la diferenciación cultural (García Canclini 2000, Appadurai 2001, Ortiz 2004, entre otros). "La globalización no solo homogeniza e integra culturas. También genera procesos de estratificación, segregación y exclusión social" (García Canclini 2000: 5). La intersección entre las tendencias que se difunden a escala mundial con culturas locales generan procesos de "criollización", mestizaje, hibridación (Hannerz 1998, García Canclini 2000), dando lugar a nuevas realidades culturales.

Desde mediados de la década de los noventa del siglo pasado este debate se traslada al ámbito de la sexualidad, al constatarse la centralidad del proceso globalizador en el análisis de fenómenos como la prostitución, la trata de personas con fines sexuales, el turismo sexual, las relaciones "virtuales" generadas a través de internet...y en un aspecto que centrará el interés de los investigadores: la globalización de las identidades sexuales y de género, especialmente de aquellas sexualidades no normativas. Las investigaciones realizadas, ponían de manifiesto que términos como gay, homosexual o lesbiana eran ya utilizados en los lugares más remotos (Lancaster 1988, Tai 1995). Tal y como señala a principio de los noventa Ken Plummer (1992: 17), "las homosexualidades se han globalizado". Desde entonces, numerosos autores pondrán de relieve que la globalización estaba provocando la expansión mundial del modelo de homosexualidad occidental post Stonewall (Altman 1996a, Parker 1999, Jackson 2000). En 1996, Dennis Altman calificará este proceso como global queering.

Son diversos los factores que se han utilizado para explicar la generalización del modelo de homosexual occidental: cambios económicos, medios de comunicación, migraciones, turismo, activismo de los derechos humanos, etcétera (Jackson 2001, Drucker 2004) (3). Pero el problema no es tanto explicar las razones que han conducido a la expansión del modelo gay y el de otras categorías sexuales y de género, como la significación de este proceso: ¿Se terminará por imponer a nivel mundial un único modelo de identidad que traduzca de la misma forma las relaciones sexuales entre personas del mismo sexo? ¿Nos encaminamos hacia un proceso de desaparición de las identidades sexuales y de género "indígenas"? ¿Es un hecho inevitable?

Las respuestas a estas preguntas están condicionadas por la valoración general que se tiene sobre el fenómeno de la globalización. Por un lado, nos encontramos planteamientos que la entienden como una nueva versión de la modernización, ligada a la idea de progreso, a la extensión de los derechos humanos y el respeto de la diversidad sexual; o bien, por otro, como una nueva etapa del colonialismo que conduce a la imposición del mundo occidental también en el campo de las sexualidades. Independientemente de estos 
posicionamientos, la mayoría de los investigadores aceptan dos hechos: 1) La expansión mundial del modelo de identidad homosexual occidental, 2) este proceso de expansión va acompañado de algún tipo de hibridaciones entre modelos locales y globales. Así, junto a la generalización de categorías sexuales occidentales se observa la proliferación de una variada gama de construcciones en relación a la identidad sexualidad y de género (Jackson 2000), en las que las categorías locales parecen entremezclarse con aquéllas que provienen de Estados Unidos y Europa. Algunos autores interpretan estas categorías locales de identidad de género y/o sexual como survirvals del pasado; otros, como hibridaciones, productos del entrecruzamiento de lo local y lo global.

Una cuestión central en estos debates es el papel que se le asigna a lo local y a lo global. Para Dennis Altman (1996a, 1996b, 1997, 2006) nos encontraríamos ante un proceso inevitable que conduce al global queering, en el que las diferencias locales son mínimas. Para otros autores como Manalasan (1995), Jackson (2001, 2009a) y Babb (2003), las culturas locales tienen un mayor protagonismo. Consideran que no en todos los casos lo global se esté imponiendo a lo local. El global queering puede verse como la suma de las muchas transformaciones locales que han surgido de la intersección de las influencias de las formas nacionales y transnacionales del capitalismo" (Jackson, 2009b: 387). Y es que habitualmente, la oposición entre lo local y lo global encierra una visión dicotómica de la realidad, donde lo local se asimila a lo autóctono, a lo "indígena" y a lo homogéneo, mientras lo global encarna lo importado, lo moderno, y lo heterogéneo (Corboz 2009). Este binarismo marca una buena parte de los trabajos que se realizan sobre este tema, generando una jerarquía entre lo local y lo global que termina dibujando un universo homosexual globalizado de muy diferente signo, en positivo, "Gay Planet", o en negativo "McGay" (Boelstorf 2005).

\section{La homosexualidad globalizada}

Hoy está claro que la globalización de la economía y el desarrollo tecnológico de los medios de comunicación "ha ayudado a crear una identidad lésbico-gay internacional, que de ninguna manera está limitada al mundo occidental" (Altman 2006: 140). Altman asocia este proceso a una nueva etapa del capitalismo y considera que la globalización no disminuye las diferencias culturales sino que las redistribuye, "de tal forma que algunos estilos y modas de consumo, se internacionalizan, mientras que la división de clase se fortalece, a menudo, a través de fronteras nacionales" (Altman 2006: 47). El énfasis se pone así en lo global, por eso, aun aceptado que en ocasiones esta expansión va acompañada de algún tipo de reactivación de identidades sexuales y de género locales, las considera como algo meramente testimonial, formas tradicionales que estarían abocadas a la desaparición. Desde este posicionamiento se hace una lectura positiva de la expansión del modelo occidental, que se equipara con modernidad y liberación frente a una sexualidad tradicional opresiva (Manalansan 1995, Pua 2005). Para Altman (2006: 152): "Las nuevas identidades sexuales implican la pérdida de confort de ciertas tradiciones, pero ofrecen nuevas posibilidades a quienes las adoptan, y los activistas de los países no occidentales sacarán provecho de maneara consciente de ambas tradiciones". Así se critican las investigaciones, especialmente antropológicas, que poniendo el acento en lo local presentan una visión "romántica" de la homosexualidad en las "culturas tradicionales". Estos trabajos, calificados en ocasiones como anthroqueers (Bacchetta 2002), tienden idealizar la tolerancia hacia la homosexualidad en otras culturas y reivindican la existencia de identidades homosexuales asociadas habitualmente a un tercer género.

Sin embargo, este carácter supuestamente "liberador" se ha puesto en cuestión desde las perspectivas que inciden en la vinculación entre modelos occidentales de sexualidad en general ( $\mathrm{y}$ homosexualidad en particular) y procesos de expansión colonial (Manalansan 1995 y Ferguson 1999, entre otros). Para estos autores la defensa del modelo globalizado parte de una posición etnocéntrica que entiende que las formas occidentales están en la cumbre la evolución. Y no les faltan razones, la colonización ha ido acompañada de procesos de dominación (ya desde la fase previa a la globalización: la mundialización), tal y como se puso de manifiesto en la imposición de nuevos modelos de moralidad, por ejemplo, en el caso de América Latina, donde se acaba con toda una serie de costumbres "bárbaras", entre otras, las formas de vivenciar el cuerpo y la sexualidad que no se correspondían con la sexualidad normativa de los invasores. Al fin y al cabo las diferencias sexuales eran una forma de establecer jerarquías entre las sociedades civilizadas y salvajes, al mismo tiempo que una forma de legitimar la conquista (4). Para Jackson (2009a), con demasiada frecuencia, se dan por hecho los efectos de la globalización y serían necesarias investigaciones empíricas que nos permitan entender cómo se han ido produciendo estas transformaciones. Efectivamente, ello nos 
posibilitaría, por ejemplo, analizar el significado de los préstamos lingüísticos desde el propio contexto local, y es que el uso de terminologías importadas puede resultar bastante engañoso (Tan 1995, Lancaster 1988, Boellstorff 2004 y 2005, Berek 2006, Jackson 2009). En ocasiones, únicamente se sustituyen términos locales por gay, lesbiana u homosexual sin que supongan cambios sustanciales en el modelo. Otras veces el uso es mucho más innovador y se le otorgan significados distintos al original. De la misma forma, la adopción de determinados símbolos, lenguaje y estilos de vida no tiene porqué significar que las identidades sean las mismas. Si partimos de que la sexualidad humana es simbólica (Plummer 1991), superando los viejos postulados biologícistas (Nieto 2003), es central tener en cuenta el contexto cultural y el significado que se le otorgan a las prácticas (Adam y otros 1999) en función de cada ámbito local, que no puede ser entendido como un mero receptor de transformaciones inducidas (Berek and Adam 2006: 133). "No hay razón para suponer que gays y lesbianas del tercer mundo estén condenados a desprenderse por completo de esas identidades para asumir las modernas" (Drucker 2004: 16). Sería peligroso sugerir una convergencia en los estilos de vida homosexual -a través del mundo- en una auténtica homosexualidad universal. Además, cada una de las culturas nacionales y locales tiene su propia riqueza, sus propias estrategias políticas, su propia singularidad. Ciertamente, la globalización viene acompañada de la intensificación de lo local (Plummer 1992: 17).

Jeffrey Weeks señala que las conexiones globales están debilitando los modelos tradicionales de homosexualidad, sin embargo, el contacto entre distintas identidades sexuales está generando nuevas formas y patrones (Weeks 2007: 218). Las hibridaciones entre identidades locales y globales son una evidencia. Pero hay autores que van más allá al cuestionar los análisis universalizadores, que en cierta medida podríamos clasificar como "difusionistas". La explosión de identidades que se observan en algunas sociedades no respondería únicamente a la fuerza de la globalización ni se trataría exclusivamente de hibridaciones entre formas antiguas y modernas (Manalasan 1995, Parker 1999, Jackson 2000, Boellstorff 2003, Drunker 2004). Así, Peter Jackson (2009a y 2009b) considera, a partir de su investigación en Tailandia, que la proliferación de identidades sexuales en este país ni son restos de formas antiguas ni son el producto de la confluencia hacia occidente. Para este autor, la aparición de nuevas identidades de género y sexuales sería anterior al proceso globalizador e insiste que en el análisis de las identidades sexuales es necesario tener en cuenta las transformaciones internas de las sociedades, y la evolución de lo local partir de los contextos nacionales. En la misma línea, Blackwood (2005) argumenta que las subjetividades lésbicas que estudia en la localidad Indonesia de Padang no pueden entenderse como premodernas frente a la supuesta modernidad de las identidades gays o lésbicas. Estas subjetividades serían consecuencia de los procesos modernos que ocurren en Indonesia, tanto a nivel nacional como transnacional. "Los discursos dominantes sobre sexualidad en Indonesia son un producto del Estado, los clérigos islámicos, y los líderes étnicos regionales” (Blackwood 2005: 227).

La dualidad entre lo global y lo local que se observa en un buen número de investigaciones se ha intentado salvar utilizando conceptos alternativos como es el caso de sexualidades transnacionales (Grewal y Kaplan 1994, Manalansan 1995, Puar 2001, Blackwood 2005). El término trasnacional, tal como reconoce Hannerz (1998) tiene un alto grado de ambigüedad pero es menos grandilocuente que globalización y ayuda a considerar la localidad de forma activa no como mera receptora de los procesos globales. Lo global y lo local no se excluyen mutuamente sino que interaccionan de forma compleja. Variables como el género, la etnia o la clase social son fundamentales para entender cómo se articulan en contextos sociales concretos las tendencias globales. En este sentido Blackwood (2005) habla de "Cultural location" (ubicación cultural). "Lo que constituye un lugar cultural son los flujos globales, regionales e históricos que han creado discursos específicos, conocimientos y formas de entender el mundo en áreas específicas" (Blackwood 2005: 222). A su vez, Boellstorff (2003) introduce la noción de dubbling culture. Sirviéndose de la metáfora del doblaje propone, en un sentido metafórico, que los gays y lesbianas indonesios "doblan" a los sujetos occidentales, de la misma forma que se hace en el cine o en la televisión. Los actores sociales no se limitan a reproducir lo que llega de fuera sino que lo interpretan y hacen suyo. No estaríamos ni ante una traducción literal ni completamente libre. Sería una especie de bricolaje en el que el discurso original occidental se filtra a través de una lente nacionalista. Este proceso de doblaje permite a los gays y lesbianas indonesios verse a sí mismos como parte de una comunidad global a la vez que "auténticamente" indonesios.

\section{Diversidad homosexual occidental}


Es bastante significativo que el amplio debate sobre la globalización de las identidades sexuales se centre mayoritariamente en aquellas identidades no normativas y, en cambio, se le haya prestado mucha menos atención a la heterosexualidad (Villaamil 2004, Cáceres 2013). Da la impresión que mientras la homosexualidad está sometida a profundas transformaciones no ocurre lo mismo con la heterosexualidad. Si por un lado, hay bastante unanimidad en aceptar que lo que entendemos como homosexualidad es una construcción occidental relativamente reciente, muy diferente a otros modelos que se dan en otras culturas y en otros momentos históricos (5); por otro, aun aceptando que el término heterosexual también es occidental y contemporáneo, se toma implícita o explícitamente como una especie de universal "natural" que no es necesario comparar. Mientras que en las "homosexualidades" se pone el acento en las diferencias, en las "heterosexualidades" se insiste en las semejanzas, obviando que, aun siendo un modelo social generalizado, subsisten formas culturales que se convierten en especificidades (6). Los cambios ocurridos en las identidades generadas a partir de relaciones entre individuos del mismo sexo no pueden entenderse al margen de la evolución sufrida por la heterosexualidad o, si se prefiere, por la heteronormatividad.

Si es muy diferente el tratamiento que se da a las homosexualidades, entendidas en plural y a la heterosexualidad en singular, no lo es menos el que se produce entre identidades sexuales occidentales y no occidentales. Los modelos no occidentales se suelen calificar de tradicionales y son concebidos de una forma esencialista, ya que se interpretan como intrínsecos a la cultura e inalterables en el tiempo. Pocas veces se presta atención a su origen, su evolución y a las posibles influencias externas, lo que lleva a pensar que la sexualidad no ha cambiado hasta la llegada del modelo occidental, olvidando que antes de la globalización también existían contactos entre culturas. En este sentido Jackson (2009a) resalta la necesidad de incorporar las historias de las culturas homosexuales más allá de Occidente.

La diferencia que se señala habitualmente entre el modelo gay que derivaría de la evolución occidental del siglo XIX y los modelos considerados "tradicionales", radicaría según Altman (2006) en que la construcción de la identidad sexual no se liga automáticamente al género, enfatizándose la centralidad de las relaciones sexuales y su vinculación con la afectividad. De esta forma los mundos "homosexuales" (7) refuerzan su carácter público, asociados a un conjunto de estilos de vida y comportamientos.

Precisamente la mayor o menor centralidad de "la sexualidad" y "el género" está habitualmente en la base para diferenciar los modelos de homosexualidad considerados "tradicionales" del modelo gay (8). Frecuentemente, para reforzar esa idea se recurre al hecho corroborado en numerosas sociedades en las que en las relaciones sexuales entre hombres únicamente se ha considerado homosexual al pasivo: Omán (Wikan 1977), Marruecos (Makhlouf Obermeyer 2000), Brasil (Parker 1999), Nicaragua (Lancaster 1988), Perú y España (Valcuende 2011). Para Altman (2006), en las sociedades tradicionales hay una confusión entre sexo y género, así el verdadero hombre homosexual es el que se considera como mujer.

Detrás de estos debates subyace la compleja relación entre sexualidad y género (9). Tal y como señala Jackson (2000: 418), cabría preguntarse si a la hora de construir identidades homosexuales fuera del mundo occidental no se tiene en cuenta el deseo, o si en la construcción de las identidades gays y lésbicas en occidente no sigue teniendo peso el género. Tal como comenta Jackson (2000: 409) en relación a Tailandia: "Mientras que la oposición masculino/femenino subyace en todas las formas de expresión erótica en Tailandia, la idea de que estos dos dominios se entrecruzan en diversos grados con el cuerpo y el deseo de todos los individuos también es fundamental para la comprensión de la diferencia de género/sexo". También Blackwood (2005) lo confirma en Indonesia. Aunque reconoce que en Padang, la localidad que estudia, ser lesbiana, tombois, se entiende normalmente como una expresión de género y no de sexualidad; no lo interpreta como un tipo de identidad premoderna frente a las identidades sexuales occidentales. Los tombois no ven el género y la sexualidad como algo distinto, representan su deseo sexual en relación con su subjetividad de género (2005: 229). Estas identidades son modernas en el sentido que reflejan una interpretación de los discursos sobre género y sexualidad, tanto nacional como transnacional, pero aquí nos surgen varías preguntas ¿Qué es una identidad "moderna"? ¿Es la identidad gay, o como lo definen algunos la "cultura gay", unitaria?

Habitualmente en el debate sobre la globalización de las identidades gays se da por hecho que existe un modelo de homosexualidad occidental homogéneo, cuando no una única "cultura gay" (10). A lo sumo se hacen algunas matizaciones entre Europa y Estados Unidos, subrayando el supuesto mayor comunitarismo de los homosexuales estadounidenses, que se evidenciaría en los "ghettos" gays (Altman 2006). Sin embargo, convendría preguntarse hasta qué punto se reproduce en todo occidente el mismo modelo y de la 
misma forma. El mundo occidental no es un bloque monolítico y al igual que ocurre en otras sociedades el modelo dominante se articula con otros.

No solamente es posible diferenciar entre Europa y Estados Unidos, sino también entre el norte y el sur europeo, o entre el este y el oeste del continente. Incluso encontramos diferencias apreciables dentro de un mismo país. Así, en el sur de Europa, en España, los "homosexuales" andaluces presentan diferencias no solo con el modelo genérico occidental sino también con el de otras regiones españolas (Guach 1991, Cáceres Feria y Valcuende del Río 1999). Igualmente nos encontramos formas específicas de sexualidad en el caso italiano a partir de modelos como los "femminellos" (Zito y Valerio 2010 y 2013).

Los trabajos sobre diásporas gays han puesto de relieve que en el corazón del mundo occidental, tanto en grandes ciudades de Europa, como Londres, o de Estados Unidos, como Nueva York, coexisten distintas formas de identidades homoeróticas. Los homosexuales procedentes de los rincones más lejanos del planeta quedan excluidos del modelo dominante por razones de género, "raza", etnicidad o clase social, produciéndose articulaciones con las formas procedentes de sus culturas de origen. Estos trabajos contradicen la imagen que frecuentemente se proyecta en relación a un modelo gay que habría llegado a una etapa final definitiva o que evoluciona en una única dirección.

\section{La homosexualidad en el contexto andaluz}

Uno de los rasgos que más se han utilizado para caracterizar las relaciones sexuales entre hombres en el mundo mediterráneo ha sido la distinción entre pasivos y activos. Se ha constatado desde la antigüedad clásica (Murray 1997, Crompton 2003) que mientras los hombres que penetraban no adquirían la condición de "menos hombres", eran feminizados los que en la relación adoptaban un papel receptivo. Este patrón de sexualidad ha sido definido como modelo mediterráneo (Vázquez y Clemison 2011) (11), muy vinculado con el sistema de sexo género propio de esta área (Gómez 2009), caracterizado por una fuerte polarización masculino / femenino que rige la organización de la sociedad (Peristiany 1968, Pitt Rivers 1979, Bordieu 2000).

En el Mediterráneo la sexualidad ha mantenido una cierta flexibilidad, a partir de la cual se podía transitar en relaciones sexuales entre hombres sin que por ello se perdiese "la masculinidad", a diferencia del modelo de homosexualidad que se ha comenzado a generalizar, a partir de la década de los sesenta del siglo pasado, que niega lo que para generaciones mayores no fue extraño, por ejemplo, los juegos homoeróticos entre hombres en diversas fases de su vida (Guasch 2011). Este carácter antiesencial en las relaciones sexuales (Guasch 2000) posibilitaba transitar fronteras, lo que no significaba que algunas de estas prácticas fuesen penalizadas. Una cuestión clave es conocer cuándo estos comportamientos generan "identidades" habitualmente estigmatizadoras. El homosexual en el Mediterráneo es el hombre afeminado, sexualmente pasivo. En este sentido, no parece diferenciarse mucho de otras zonas del mundo. La transgresión de género, el afeminamiento, es uno de los rasgos que unifica las "homosexualidades" de numerosas culturas y que diferencia la sociedad occidental contemporánea de lo que ha que se ha denominado como "sexualidades tradicionales". Sin embargo, es simplificador reducir a este único elemento las diversas formas de vivir la sexualidad entre individuos del mismo sexo en múltiples sociedades. La mayoría de las veces, lo que se denomina afeminamiento no es exclusivamente la reproducción por hombres de comportamientos asignados a mujeres sino, más bien, el que los hombres no se ajusten a las conductas masculinas dominantes. Por eso, no existe una única forma de afeminamiento, no solo porque lo que se espera de hombres y mujeres varíe de una cultura a otra, sino también porque en numerosas sociedades los afeminados adoptan roles propios que no son ni masculinos ni femeninos. ¿Reproducen los mismos modelos los zapotecos y rarámuris en México (Miano 2002, Gómez 2013), los xaniths de Omán (Wikan 1977), los kathoys de Tailandia (Jackson 2000), los bakla filipinos (Tan 1995)? Se ha utilizado el concepto tercer género o tercer sexo para referirse a categorías institucionalizadas en algunas culturas que no se ajustan a la división convencional: hombre/ mujer, masculino/ femenino (Herdt 1996). Pero son muchos los que lo consideran un concepto vago y creen que en el fondo no es más que la idealización de algunos investigadores de la "homosexualidad" exótica. Pero ¿existen formas propias de lo que hoy denominamos "homosexualidad" en el Mediterráneo?

Mientras se ha estudiado y destacado suficientemente la distinción entre pasivo y activo, se le ha prestado poca atención a la significación social de estas categorías y a los roles socialmente asignados a los 
hombres que no se corresponden con el modelo de masculinidad dominante. De hecho, la etiqueta de afeminado ha servido para homogenizar categorías diferentes. La tendencia a unificar bajo una misma significación el sentido de las prácticas nos puede y de hecho nos lleva a importantes errores conceptuales. La realidad de la sexualidad es mucho más compleja y no puede ser descontextualizada del ámbito cultural en el que se desenvuelve. En el caso andaluz nos encontramos con que los hombres que no responden a los cánones de masculinidad dominante han cumplido funciones determinadas a diversos niveles: laboral, familiar, artístico y simbólico ritual.

\section{Los afeminados andaluces, ¿un modelo de sexualidad específico?}

Los escasos estudios existentes sobre la homosexualidad en Andalucía ponen de manifiesto el importante desarrollo discursivo e identitario que adquirió en el siglo XX el hombre afeminado, al que denominaremos a partir de ahora, utilizando la terminología popular, mariquita (12). Es cierto que este término se utiliza en toda España. Sin embargo, mientras en algunas zonas no hay apenas un desarrollo discursivo, como tampoco hay funciones sociales definidas públicamente, en el sur, especialmente en Andalucía, el mariquita responde a un modelo social mucho más elaborado y visible, con un cierto reconocimiento social en determinados ámbitos. Es precisamente su mayor presencia en contextos públicos, artísticos y rituales, uno de los elementos que contribuye a individualizar al mariquita andaluz de los afeminados de otras zonas del país en las que solían ser invisibilizados. Este fuerte contraste no es el único. Los mariquitas del sur quedan caracterizados a través de los rasgos estereotipados con los que se definen en España a los andaluces: carácter festivo, humor, religiosidad, una estética popular... De esta forma, el mariquita del sur representa la encarnación de la cultura andaluza. Una cultura con un carácter eminentemente popular que explica que mayoritariamente este modelo sea el de los afeminados de las clases subalternas. Evidentemente, en Andalucía no ha habido ni hay una única forma de vivir las relaciones entre hombres. No todos los "homosexuales" andaluces han respondido, ni responden a este modelo. Al contrario, son muchos los que se tratan de distanciar del mismo al considerarlo conservador y caduco. Así, por ejemplo, los afeminados andaluces de las clases medias y altas procuraban alejarse de un modelo que suponía, además del reconocimiento de la "homosexualidad" estigmatizadora, una degradación de clase. En la actualidad, muchos "homosexuales" de las clases medias y bajas toman otros referentes muy alejados del "mariquita andaluz" que se ve como algo del pasado. Por lo tanto, vemos como el modelo del mariquita andaluz queda definido por las variables: etnia y clase social. Esta vinculación entre determinadas formas de "homosexualidad" y clase social la encontramos en numerosas sociedades. Así por ejemplo, los warias, travestis indonesios, proceden mayoritariamente de las clases populares (Blackwood 2005). Entre los muxes zapotecos del Istmo de Tehuantepec hay importantes diferencias en relación al travestismo, entre los que proceden de los barrios populares y los que viven en barrios de clase media (Miano y Gómez 2009).

En todo caso el término "mariquita" engloba una realidad social diversa, que va desde el travesti (posteriormente transexual) al afeminado; desde aquellos hombres que se muestran públicamente hasta los que tratan de amoldarse a los cánones sociales. Como señalamos anteriormente, un mismo término puede hacer referencias a categorías diversas, abarcando realidades que progresivamente se han ido diferenciando en función del cada vez mayor peso de la sexualidad en la definición identitaria de los individuos.

La figura del mariquita, ridiculizada habitualmente e instrumentalizada por el poder en la música, el cine o el teatro como una forma de reafirmación en negativo de la identidad masculina y femenina, es mucho más que una imagen, sea de opresión o subversión (como en cierta media fue a partir de los años setenta). Representa la vivencia y la cotidianidad de unos seres humanos en un contexto cultural específico. Los mariquitas han formado parte de la realidad social de Andalucía, que al mismo tiempo que los reconocía socialmente lo hacía en cuanto que les negaba su propia sexualidad en el ámbito "público", aunque, implícitamente, se intuía que mantenían relaciones sexuales con otros hombres considerados "heterosexuales". De esta forma el mariquita se ha movido en un mundo liminal, oculto y secreto, aunque al mismo tiempo, como veremos posteriormente, ha ocupado y ocupa un plano central en determinados ámbitos festivo-rituales.

El mariquita se desenvuelve y es representado entre el mundo masculino y femenino pero es visibilizado de forma específica. Su cuerpo es de hombre, y ese elemento es central a la hora de entender su posición 
simbólica pero, al mismo tiempo, no es un "verdadero" hombre. Nuevamente las representaciones en torno a la sexualidad están profundamente imbricadas por las lecturas sociales de género. A su vez, el mariquita tiene cualidades consideradas como femeninas. Esta combinación de atributos masculinos y femeninos nos ayuda, precisamente, a explicar algunas de las funciones claramente definidas, que les han sido asignadas en muchas poblaciones andaluzas.

En el ámbito laboral hay faenas que han estado asociadas a "los mariquitas", fundamentalmente trabajos de autónomo, en cierta medida vinculados con espacios considerados femeninos. Hay varias razones que nos pueden ayudar a entender esto. La primera y fundamental es que los hombres afeminados se han protegido de algunos ámbitos masculinos donde estaban condenados a ocupar una posición subsidiaria, pero al mismo tiempo no podemos olvidar la discriminación que han experimentado en determinados contextos que no se corresponden con sus espacios "naturales" (un hecho que se pone especialmente de manifiesto en el caso de los travestis y transexuales). Y es que las significaciones corporales se reproducen también en el ámbito laboral. Son precisamente las lecturas en torno a la significación del cuerpo como se explican socialmente sus "cualidades" singulares. Los mariquitas tienen la sensibilidad de las mujeres, lo que les permite bordar o cortar el cabello tan bien o más que las propias mujeres (no olvidemos que su cuerpo indica una posición, de entrada, superior a las mujeres), pero al mismo tiempo tienen la posibilidad de combinar esa destreza "femenina" con la fuerza y "habilidades" de los varones. Una informante nos comentaba en relación a un mariquita que "no le faltan casas, porque además de limpiar como una mujer tiene la fuerza de un hombre, entonces lo prefieren a él porque si hay que retirar un mueble o bajar una lámpara puede hacerlo como un hombre".

Evidentemente la asociación ideal entre trabajo y género no implica que los mariquitas necesariamente realizasen solo estas funciones, como bien sabemos los modelos sociales nos ayudan a entender las concepciones de una sociedad ante "el deber ser", lo cual no implica que esta asociación sea automática, y más, como veremos posteriormente, cuando esta realidad se ha complicado enormemente a partir del proceso de hibridación de viejos y nuevos modelos, sin olvidar las propias transformaciones del modelo "tradicional" a lo largo del tiempo. En todo caso, se aprecia una cierta especialización laboral en muchos pueblos andaluces. Así, por ejemplo, encalar o pintar ha sido una labor eminentemente femenina en una buena parte de Andalucía. Estas actividades están relacionadas con el engalanamiento de la casa, pero también con la limpieza, ambas tareas vinculadas socialmente al mundo de las mujeres. Sin embargo, es frecuente que en una buena parte de Andalucía este trabajo se asocie a los mariquitas, precisamente porque en ellos se combinan cualidades femeninas (limpieza y esmero) y masculinas (fuerza y destreza), y por tener posibilidades de desenvolverse en la esfera pública y en la esfera privada, donde el acceso de otros hombres podría ser cuestionado. El segundo ámbito central asociado con los mariquitas en la sociedad pre-gay andaluza es la familia. Guasch lo define de una forma excelente a partir de las confidencias de una informante en el Rocío: "Pues sí, he parido seis varones. Ni una hembra ¡Con el trabajo que da tanto hombre y no tengo a nadie que me ayude! Si al menos uno hubiese salido mariquita tendría algo de ayuda en la casa" (Guasch 1991: 53).

Efectivamente el mariquita va a desarrollar labores y trabajos que en ningún caso realizaría un hombre con mayúsculas en el ámbito doméstico, relacionados con las actividades femeninas de "el cuidado". El espacio doméstico en cuanto ámbito femenino es un espacio propio de: mujeres, niños y mariquitas. De hecho tal y como señala Cantero (2003), la socialización de los varones está marcada por un proceso progresivo de rupturas, que obligan a salir al varón de un mundo eminentemente femenino como es el hogar y la iglesia. En el caso del mariquita la casa y, como veremos posteriormente, la iglesia jugarán un papel central en su vida (13). Los mariquitas no sólo realizan actividades consideradas femeninas sino que además suelen cumplir un papel importante en el cuidado de los padres mayores. Al no tener habitualmente una familia de descendencia continúan manteniendo relaciones con la familia de ascendencia, papel habitualmente cumplido por las hijas solteras.

No es casual que sea precisamente el ámbito de la iglesia el que ocupe un papel central en un grupo que se mueve entre el mundo masculino y femenino. La iglesia ha sido y es considerada un ámbito básicamente de mujeres, tal y como señala Moreno (1972): "El ser ratón de sacristía" no da prestigio a los hombres, es más puede ser incluso un motivo para ser acusado de afeminado. Efectivamente, pasar demasiado tiempo en la Iglesia no es algo que normalmente dé demasiado prestigio a la mayoría de los varones; mejor dicho, a aquellos hombres que se vinculan al modelo de masculinidad dominante. Sin embargo, para el hombre afeminado, la iglesia le supuso buscar un hueco en el ámbito de lo social, que le permitió tener una 
significativa proyección y reconocimiento. De hecho, su presencia en una buena parte de los aspectos organizativos vinculados con el espacio de la iglesia y con las acciones simbólicas religiosas ha sido y continúa siendo más que notable. Nuevamente las labores de las que se ocupan los mariquitas están, en teoría, fundamentalmente vinculadas con tareas femeninas. Un proceso que se ha ido modificando a lo largo del tiempo. En este sentido, es interesante observar la progresiva especialización de algunas funciones y la sustitución de las mujeres por los mariquitas. Al menos, desde principio del siglo XX, con el auge adquirido por la Semana Santa y el desarrollo de las hermandades religiosas en muchas ciudades y pueblos andaluces, hemos asistido al progresivo desplazamiento de las camareras o mujeres encargadas del cuidado de las imágenes. Las hermandades se han convertido en las principales asociaciones andaluzas cuyas funciones superan con mucho lo puramente religioso, jugando un papel destacado en el ámbito de la identidad, la sociabilidad o lo político, constituyéndose en importantes espacios de prestigio (Moreno 1985). En este contexto, no es extraño que tareas como vestir las imágenes religiosas hayan pasado a manos masculinas (14). En la actualidad, en ciudades como Sevilla, Córdoba o Málaga la mayoría de los encargados de vestir las Vírgenes que procesionan son mayoritariamente hombres. Sin duda la figura más directamente, aunque no la única (15), asociada al mariquita en el ámbito religioso, es la del vestidor, encargado de ataviar imágenes religiosas, especialmente las que ocupan un lugar más destacado en la religiosidad andaluza, las Vírgenes:

“En Castilleja, esa es sin embargo una tarea realizada por 'los maricas', por cuanto se considera que ellos son tan poseedores de esa cualidad femenina 'del bueno gusto' como las mismas mujeres, a las que llegan incluso a superar en este aspecto. Por esta razón, cada hermandad tiene designado a uno de ellos, que ayudado por varios más y por alguna mujer, se encarga de preparar las imágenes y en general del adorno de la iglesia para cualquier culto importante" (Aguilar 1983: 127).

Llama la atención la centralidad que adquieren estos hombres en un hecho tan "sensible". Ver una imagen desnuda puede constituir un acto totalmente sacrílego:

"Nadie puede estar presente y menos aún los hombres, por lo que estos, incluso los de la junta de gobierno, se apresuran a abandonar el templo cuando la tarea va a dar comienzo. En esto existe un auténtico pudor, un sentimiento de vergüenza, incluso de sacrilegio, ante lo que se considera una verdadera figura femenina desnuda, y más aun con la valoración y la categoría reverencial que posee la Virgen -la Madre- para sus devotos (...). La operación de vestir a la imagen puede durar varias horas, ya que se realiza con el cuidado y esmero que esta merece. En primer lugar se procede a desvestirla y acto seguido los presentes comenzaron a discutir sobre la ropa más adecuada y acto seguido los presentes comenzaron a discutir sobre la ropa más adecuada que ponerle. Se tenía la sensación de que se hablaba de un ser vivo cuando se decía como la cosa más natural: 'Hoy le ponemos el traje azul y el manto blanco, que le sienta muy bien'." (Aguilar 1983: 179).

Tal y como señala Aguilar "los hombres" no pueden estar presentes mientras se procede vestir a la Virgen. Pero si los mariquitas acceden a este ámbito exclusivamente femenino, no sucede igual si nos referimos a las imágenes de los Cristos, especialmente los más emblemáticos, donde es menos probable que un marica sea un vestidor, tal y como ponen de manifiesto en las entrevistas que realizamos en Sevilla durante 2013. Este hecho no es ni mucho menos anecdótico y refleja/construye de forma simbólica una realidad en que estos hombres son aceptados o rechazados en función de sus cánones genéricos y/o de una posible sexualidad que se presenta o no como amenazante, en un contexto como el andaluz en el que las imágenes son mucho más que imágenes, ya que al mismo tiempo que representan una idea abstracta de virginidad o divinidad, tienden a ser "humanizadas", como han puesto de manifiesto numerosos autores (Moreno 1985).

Si bien es frecuente que los vestidores de las vírgenes sean afeminados, en la mayoría de los casos, se les exige un mayor grado de discreción que a otros mariquitas. Deben tener costumbres intachables. Por eso, no suele haber travestidos ejerciendo estas tareas. Esto hace posible que desempeñaran estas labores también hombres casados, no necesariamente afeminados. Precisamente llama la atención la importante presencia de "mariquitas" y travestidos en algunas de las procesiones andaluzas, detrás de las imágenes de la Virgen, así como la identificación de estos hombres con algunas hermandades y momentos concretos de las celebraciones religiosas (16). En torno a los vestidores de vírgenes y a todo lo vinculado con el arreglo y exorno de las imágenes se ha generado un mundo muy especializado. Existen tertulias y foros de internet donde se debate sobre la estética mariana, ya que este ámbito está sometido también a las modas. En ciudades como Sevilla o Málaga encontramos un ranking de vestidores, alcanzando algunos una 
notoriedad que supera el ámbito local, siendo contratados en otras poblaciones del territorio andaluz. El vestidor de vírgenes lejos de ser una figura del pasado se encuentra en expansión. Desde las principales ciudades de Andalucía han ido ganando terreno en poblaciones más pequeñas. Pero no es la semana santa el único momento festivo donde la presencia de mariquitas es significativa, en otras celebraciones como el corpus, por ejemplo, en la ciudad de Sevilla, participan en el montaje y del exorno de los altares que se sitúan en las calles centrales de la ciudad. El Rocío es otra de las celebraciones donde la relevancia de los mariquitas andaluces es significativa, no solo por el papel que juegan en los preparativos de algunas hermandades, sino, también, por su visibilización durante la romería (17).

La significativa relevancia social de los mariquitas se pone especialmente de manifiesto en los pueblos que se estructuran en torno a mitades (18). Aguilar destaca cómo, en las poblaciones del Aljarafe sevillano, en el enfrentamiento ritual que por unos días divide a las localidades, los mariquitas adquieren un especial protagonismo en la canalización del enfrentamiento simbólico.

"Hay quienes se identifican plenamente con el ambiente y expresan tanto su grado de adhesión a su hermandad como su desprecio a la contraria de forma muy evidente, llegando a extremos inusitados. Son aquellos que los castillejeros llaman los 'más exaltados', entre los que destacan los 'maricas' (es este el término utilizado en el pueblo para referirse a ellos). Estas personas (...) mantienen una estrecha relación con las hermandades y están ampliamente representadas en las dos. Su status sexual es reconocido en Castilla y su posición social no es tan marginal aquí como en otras comunidades. Su presencia en todas las celebraciones es especialmente importante, en la medida que a ellos, por aceptárseles estar al margen de la mayoría de las pautas sociales de comportamiento vigentes en la comunidad, les está permitida una actuación que estaría mal vista -aunque sea sentida como necesaria- en cualquier otra persona. De esta forma los 'maricas' se convierten en los máximos protagonista de la hostilidad, asumiendo el papel de portavoces de los demás castillejeros de cada hermandad. De ellos todo el mundo espera comportamientos expresivos y atrevidos, tanto a la hora de subrayar su pertenencia como su oposición a los contrarios. Comportamientos que todos aplauden y suscriben, pero que les está vetado imitar plenamente. La mayor parte de estos vítores son lanzados por los 'maricas' delante del Simpecado, mientras son levantados a hombros por otras personas de forma que sus voces sean suficientemente escuchadas por todos los presentes, incluidos los de la mitad contraria" (Aguilar 1983: 122-123).

En el ritual descrito por Aguilar se pone de manifiesto la funcionalidad social de esta figura. Sus actos no serían propios de las mujeres, en un contexto publico de enfrentamiento ritual, pero tampoco de los "hombres" ya que podría derivar en enfrentamientos directos, por lo que son estos hombres "femeninos" los que pueden ocupar un plano simbólico de especial relevancia, que sólo puede ser entendido desde su posición liminal tanto en el mundo masculino como femenino.

No es solo el ámbito festivo ceremonial el único espacio donde los mariquitas andaluces han ocupado una posición destacada. Lo mismo que ocurre en otras latitudes, el papel que han jugado en el mundo artístico, especialmente musical, ha sido relevante. Así sucede en el género conocido como copla, caracterizado por su carácter eminentemente femenino, los mariquitas encontraron un espacio donde podían dar rienda sueltas a una estética y a unas formas de expresión. Quizás sea el malagueño Miguel de Molina (19081993), con su amaneramiento y su estética provocadora, el prototipo de mariquita andaluz coplero, pero no es el único (García Piedra y Gil Siscar 2007). La presencia de mariquitas han sido tan relevante que este género ha quedado asociado a la homosexualidad. Probablemente sea Falete el cantante que en la actualidad mejor encarne este prototipo.

Pero, también, en una música tan masculinizada como el flamenco han sido muchos los artistas abiertamente "homosexuales". Es llamativo que a finales del XIX en los cafés cantantes sevillanos actuaran algunos hombres travestidos. Es el caso del malagueño conocido como la Escribana, que cantaba y bailaba en compañía de la bailaora granadina Carmen la Carbonera (Triana 1986: 104-105), escandalizando a la presensa moralista del momento.

En todo caso, si esta ha sido la representación dominante del mariquita hasta los años noventa del siglo pasado, esto no significa, primero, que esta representación haya sido estática ni, segundo, que el modelo que denominamos "gay" no haya influido de una forma notable en la sociedad andaluza, como veremos a continuación. 


\section{Las transformaciones del modelo de "homosexualidad" en Andalucía}

En un mundo donde ha irrumpido un nuevo modelo de homosexualidad, que viene a representar una forma más explícita de vivir la sexualidad entre hombres y que se identifica como signo de los nuevos tiempos y de modernidad, la figura del mariquita andaluz puede parecer un tanto anacrónica. Para muchos simboliza la opresión vivida por miles hombres durante décadas y estaría condenada a la desaparición. Sin embargo, este pronóstico, o deseo, es un tanto simplificador. Los cambios que operan en el ámbito de la cultura son mucho más complejos y la sexualidad como parte constitutiva de la cultura no es ajena a estos procesos. Las transformaciones que afectan a la sexualidad en general se ponen también de manifiesto en el caso de la significación de los cánones genéricos y sexuales de los disidentes sexuales andaluces. Como ya hemos señalado es imprescindible en el análisis de los efectos de la globalización tener en cuenta cómo se articula lo global con lo local. La forma en que al menos una parte de los andaluces asumen el modelo gay no es la misma que en otras zonas de España o de Europa.

Aunque en nuestra exposición hayamos presentado la figura del mariquita de un modo sincrónico, no significa que sea un modelo estático. Ha estado sometida a todas las transformaciones sufridas por la sociedad española (Mira 2004), en general, y la andaluza, en particular, a lo largo del siglo XX. En este sentido, las importantes transformaciones que se dan a partir de la década de los sesenta provocarán cambios notables en este modelo. Tal como señala Oscar Guasch (1991), la fuerte emigración que vivió Andalucía en esa década contribuyó a la expansión del modelo del mariquita andaluz a otros ámbitos del Estado pero, a su vez, supuso la posibilidad para muchos andaluces de poder vivir una sexualidad más libre al margen de una sociedad que al mismo tiempo que les reconocía públicamente les negaba su sexualidad. Sin duda la figura que mejor define estas transformaciones es la del pintor Ocaña (19), que huye de su pueblo natal y en Barcelona recrea un mundo artístico marcado por dos hechos, el primero tiene que ver con su origen andaluz, y el segundo con su sexualidad. La figura de Ocaña reproduce, por un lado, el modelo más tradicional de mariquita andaluz, pero al mismo tiempo lo subvierte haciendo explícita su sexualidad y jugando con los elementos religiosos, a partir de los cuales aquellos hombres que no respondían a los cánones genéricos y sexuales eran identificados en Andalucía. La vida de Ocaña refleja un hecho que posteriormente, y a partir del proceso de "modernización" de la sociedad andaluza, supondrá un cambio radical en el modelo tradicional de mariquita, como es la progresiva visibilización de una sexualidad que había permanecido en el ámbito de lo privado. Sin duda, uno de los factores más importantes en esta evolución tuvo que ver con la influencia de nuevos modelos en los que la sexualidad entre hombres dejaba de formar parte, parafraseando a Llamas (1998) del mundo "presocial" y "privado". El papel de los medios de comunicación, la aparición de un incipiente movimiento social, y factores como el turismo (20), entre otros, serán centrales en las transformaciones experimentadas en relación a los modelos sociales construidos en torno a las relaciones sexuales entre hombres.

El modelo habitualmente "asexuado" del mariquita, a partir de estos elementos, está experimentando modificaciones importantes. Pero la aparición del modelo gay no ha supuesto, ni mucho menos, la desaparición de las formas tradicionales, aunque al mismo tiempo ha posibilitado lo que ya era un hecho, al explicitar también a nivel identitario la pluralidad de significaciones de las relaciones sexuales entre hombres. La confluencia del modelo gay y del modelo "tradicional" no está exenta de conflictos, tal y como se pone de manifiesto en los homosexuales vinculados con el ámbito de la lglesia y de las hermandades (21), y es que la homosexualidad pregay y gay que definiera Guasch (1991) conviven en un mismo tiempo histórico, influyéndose mutuamente, hibridándose. Hoy confluye el mundo de "los capillitas", "los vestidores" y los desfiles procesionales de Semana Santa con el día del orgullo gay, las discotecas y el matrimonio homosexual, que se articulan de forma desigual en función de la posición de clase, el lugar de origen y el contexto social y familiar, permitiendo diferentes niveles de visibilización. En todo caso, y aunque siguen existiendo mundo paralelos, lo cierto es que también se dejan entrever procesos de interacción entre ambos contextos a medida que los nuevos roles sociales que se asignan a los definidos como gays posibilitan la visibilización de los mariquitas, que asumen, en la medida de sus posibilidades, una sexualidad más explícita, global y al mismo tiempo específica.

\section{Conclusiones}


El caso analizado de Andalucía pone de manifiesto, en relación a determinadas perspectivas sobre la homosexualidad, que:

1. El modelo supuestamente occidental no ha sido, ni es homogéneo. En Occidente, junto al modelo gay, encontramos otros que encajarían en lo que algunos autores han definido como "tradicionales", como ocurre con los mariquitas andaluces.

2. Estos modelos "tradicionales" no son estáticos. Y al igual que está ocurriendo en muchas otras zonas del mundo, en Andalucía la expansión del modelo gay, lejos de provocar una total homogeneización de las identidades vinculadas a las relaciones entre hombres, genera hibridaciones culturales y favorece la proliferación de nuevas identidades sexuales y de género. Factores como el lugar de origen o la clase social son elementos centrales a la hora de explicar la diversidad de situaciones.

3. El reconocimiento público de los mariquitas en Andalucía no ha significado necesariamente la aceptación de su sexualidad. Si bien, progresivamente y en función de los cambios sociales, la sexualidad tiende a ser cada vez más explícita.

4. El "espacio local" se ha visto influido de una forma considerable por los cambios globales, contribuyendo a la resignificación del afeminado. A su vez, lo local ha afectado notablemente en el ámbito más global, tal y como se pone de manifiesto en la propia expansión del modelo andaluz, e incluso en la significación que han adquirido algunas figuras andaluzas como Ocaña en las perspectivas globales (queer).

5. Pese a estas transformaciones los mariquitas siguen jugando un papel central en las manifestaciones culturales andaluzas, fundamentalmente las vinculadas con los contextos festivo-ceremoniales, formalmente de carácter religioso.

\section{Notas}

1. Este artículo se enmarca dentro de las líneas de investigación del Proyecto I+D Laboratorio Iberoamericano para el Estudio Sociohistórico de las Sexualidades (FEM2011-27295), financiado por el Ministerio de Economía y Competitividad. A su vez, se inserta en las líneas de trabajo desarrolladas a través del proyecto PROMETEO de la SENESCYT del Gobierno de Ecuador en la Universidad de Cuenca (Ecuador).

2. Algunos de los resultados de la investigación inicial se presentan en el trabajo de Cáceres y Valcuende (1999), posteriormente se ha trabajado en esta temática en otros proyectos de investigación. En posteriores proyectos como el mencionado en la nota 1 o el proyecto "La represión de la disidencia sexual en Andalucía durante el franquismo y la Transición" financiado por la Junta de Andalucía y coordinado por María Marco Macarro, que desarrollamos actualmente, hemos profundizado en esta temática.

3. Se destaca frecuentemente que la lucha contra el sida, fue central en este proceso. Los programas de prevención y educación de esta enfermedad han servido para difundir por todo el planeta categorías occidentales en relación a la identidad sexual (Altman 2006: 121-122). El personal técnicos y sanitario habría jugado, en este sentido, un papel fundamental (Wright 2000, Puar 2001).

4. Nos podemos aproximar a este proceso de eliminación y recreación de la historia en función de una visión heteronormativa impuesta por el colonialismo a partir de diversas investigaciones. Para una perspectiva global Gómez (2013) y para el caso de la costa ecuatoriana Benavides (2006).

5. En esta línea es pionero en España el libro de Alberto Cardín Guerreros, chamanes y travestis: indicios de homosexualidad entre los exóticos (1984).

6. Como señala Villaamil (2004) queda abierta la necesidad urgente de realizar una etnografía de la heterosexualidad.

7. Señalamos homosexuales entre comillas por cuanto que esto facilita la lectura del texto, sin embargo es preciso recordar que la "homosexualidad" en sí es un modelo histórico, que no puede ser extrapolado a 
otros contextos de forma automática.

8. Estas transformaciones han sido analizadas por Donham (2002) en Sudáfrica. En ese país, los cambios en la identidad homosexual que se producen con el declive del apartheid favorecieron la relevancia de la sexualidad sobre el género.

9. La vinculación entre sexualidad y género es sin duda una de las cuestiones centrales, que ha dado lugar a importantes debates. Compartimos los planteamientos de Rubin (1989: 184) cuando señala que "el género afecta al funcionamiento del sistema sexual, y éste ha poseído manifestaciones de género específicas. Pero aunque el sexo y el género están relacionados, no son la misma cosa, y constituyen la base de dos áreas distintas de la práctica social".

10. Sabuco y Valcuende hacen una dura crítica a una supuesta y homogénea visión de eso que se entiende como "cultura gay" (2003), Weeks (2007) lo hace en relación a una identidad gay mercantalizada.

11. Ese modelo lo encontramos también en Latinoamérica (Carrier 2001) y el mundo árabe (Murray 1997).

12. La RAE define mariquita simplemente como hombre afeminado. El mariquita ha sido considerado como "menos hombre" bien en función de una sexualidad o por no ajustarse a los cánones de género masculinos.

13. La película dirigida por Pilar Távora, Madre Amadísima, estrenada en 2009, nos aproxima a la imagen del mariquita andaluz, a través de las conversaciones que mantiene el protagonista con su Virgen.

14. Es interesante observar el progresivo desplazamiento de las mujeres por hombres "mariquitas" en algunas labores como las señalas, pero también en algunos trabajos a los que ya nos hemos referido. Así sucede igualmente con el encalado de las casas, que fue pasando en algunas zonas de Andalucía de ser una labor femenina, a ser ejercida por los "mariquitas" a medida que esta actividad se profesionaliza.

15.Vinculadas al mundo religioso encontramos otras tareas como la de bordador o, incluso, imaginero.

16. Como ocurre en la procesiones del Domingo de Resurrección en Castilleja de la Cuesta (Sevilla).

17. Su protagonismo llama la atención a muchos de los que desde fuera de Andalucía acude a esta romería. El antropólogo catalán Josep Comelles en su primera visita al Rocío se sorprendía de lo explícito de la homosexualidad en esta fiesta (Guasch 2002).

18. En numerosos pueblos de Andalucía encontramos rituales que dividen a los pueblos en mitades simbólicas. Según Isidoro Moreno, los pueblos donde se dan estas mitades "aparecerían divididos en dos sectores antagónicos y potencialmente hostiles que son percibidos en términos de superioridad/ inferioridad por todos los miembros de la sociedad según sea su contexto situacional" (1972: 107). Estas dicotomías no se superpondrían con la división de clases, sino que se entrecruzarían con ésta.

19. José Pérez Ocaña (1947-1983) es un pintor nacido en Cantillana (Sevilla) que en los años setenta emigró como tantos otros andaluces a Barcelona donde ejerció como pintor y activista. Destacando por su carácter subversivo. El documental de Ventura Pons, Ocaña retrato intermitente (1978), retrata la personalidad de este artista.

20. En España, especialmente en Andalucía el desarrollo turístico de la Costa del Sol, a partir de la década de los sesenta, tuvo una incidencia importante sobre la sexualidad, con la llegada de miles de turistas europeos que expandieron una nueva moral sexual. Lugares como Torremolinos se convirtieron en enclaves gays que atraían a curiosos de todo el país. Algo que era conocido y preocupaba a las autoridades franquistas como demuestran las fueron frecuentes las redadas policiales en los ambientes gays.

21. La expulsión en 2008 de dos famosos diseñadores que vestían las imágenes de una conocida hermandad sevillana, después de hacerse público su matrimonio, evidencian las contradicciones y los cambios que se han ido generando, a partir de la "salida del armario" de muchos de los que mantenían su sexualidad en el ámbito privado. 


\section{Bibliografía}

Barry D. Adam (y otros)

1999 The Global Emergence of Gay and LesbianPolitics: National Imprints of a Worldwide Movement. Philadelphia, Temple University Press.

Aguilar, Encarnación

1983 Las hermandades de Castilleja de la cuesta. Un estudio de antropología cultural. Sevilla, Ayuntamiento de Sevilla.

Altman, Dennis

1996a "Rupture or Continuity? The Internationalization of Gay Identities". Social Text, n 48: 77-94.

1996b "On global queering”, Australian Humanities Review, nº 2.

http://www.lib.latrobe.edu.au/AHR/archive/lssue-July-1996/altman.html,(consulta: octubre 2013).

1997 “Global Gaze/Global Gays”, GLQ: A Journal of Gay and Lesbian Studies, n 3 (4): 417-436.

2006 Sexo global. México, Océano.

Appadurai, A.

1996 La modernidad desbordada. Buenos Aires, Ediciones Trilce, 2001.

Babb, Florence

2003 "Out in Nicaragua: Local and Transnational Desires after the Revolution", Cultural Anthropology, vol.18, $n^{\circ}$ 3: 303-328.

Bachetta, Paola

2002 'Rescaling transnational 'queerdom': Lesbian and 'lesbian' identitary-positionalities in Delhi in the 1980s", Antipode: A Radical Journal of Geography, nº 34 (5): 947-73.

Benavides, Hugo.

2006 "La representación del pasado de Guayaqui. Historizando los enchaquirados", Iconos. Revista de Ciencias Sociales, $n^{\circ} 24:$ 145-160.

Bereket, Tarik (y Barry D. Adam)

2006 “The Emergence of Gay Identities in Contemporary Turkey”, Sexualities, n 9 (2): 131-151.

Blackwood, Evelyn

2005 “Transnational Sexualities in One Place: Indonesian Readings”, Gender \& Society, n 19: 221-242.

Boellstorff, T.

2003 "Dubbing culture: Indonesian Gay and Lesbi Subjectivities and Ethnography in an already globalized world", American Ethnologist, $\mathrm{n}^{\circ} 30$ (2): 225 y ss.

2004 "Gay Language and Indonesia: Registering Belonging”, Journal of Linguistic Anthropology, vol. 14 (2): 248-268.

2005 The Gay Archipelago: Sexuality and Nation in Indonesia. Princeton and Oxford, Princeton University Press.

Bordieu, Pierre

2000 La dominación masculina. Barcelona, Anagrama.

Cáceres Feria, Rafael

2013 "Diversidad sexual: contextos locales, discursos globales", en José Ma Valcuende del Río, J. Marco Macarro y D. Alarcón Rubio (coords.), Estudios sobre diversidad sexual en Iberoamérica. Sexualidades y culturas. Sevilla, Aconcagua: 15-25.

Cáceres, Rafael (y José María Valcuende)

1999 "Los mariquitas del sur. La construcción de un modelo de "homosexualidad", en Andalucía, VIII Congreso de Antropología del Estado Español. Antropología del Género, vol. 2: 101-108. 
Cantero, Pedro A.

2003 "Hombrear. Modos de aprender a ser hombres", en J. Ma Valcuende y J. Blanco (orgs.), Hombres. La construcción cultural de las masculinidades. Madrid, Talasa: 53-65.

Cardín, Alberto

1984 Guerreros, chamanes y travestis: indicios de homosexualidad entre los exóticos. Barcelona, Tusquet.

Carrier, Joseph

2001 De los otros. Intimidad y comportamiento homosexual del hombre mexicano. Madrid, Talasa.

Collins, Dana

2005 "Identity, Mobility, and Urban Place-Making. Exploring Gay Life in Manila", Gender \& Society, vol. 19, n 2: $180-198$.

Corboz, Julienne

2009 "Globalisation and Transnational Sexualities".

http://sexualitystudies.net/resource/globalisation-and-transnational-sexualities,,(consulta: noviembre 2013)

Crompton, Louis

2003 Homosexuality and Civilization. Cambridge, Massachusetts and London, The Belknap Press of Harvard University Press.

Donham, Donald L.

1998 "Freeing South Africa: The "Modernization" of Male-Male Sexuality in Soweto", Cultural Anthropology, vol. 13, no 1: 3-21.

D' Emilio, John

1983 "Capitalism and Gay Identity" in Ann Snitow, Christine Stansell, \& Sharan Thompso (edit.), Powers of Desire: The Politics of Sexuality. New York, Monthly Review Press.

Donham, Donald L.

1998 "Freeing in South Africa: The 'Modernization' the male-male in Soweto", Cultural Anthropoloiy, vol 13, n० 1: 3-21.

Drucker, Peter

2000 "Introducción: redefinición de las identidades sexuales", en Peter Druker (coord.), Arco iris diferentes. México, Siglo XXI, 2004.

Ferguson, Ann

1990 "Is There a Lebian Culture?". en J. Alln (ed), Lesbian Philosophies and Cultures: Issues in Philosophical Historiography. Albany, State University of New York Press.

García Canclini, N.

2000 "La globalización: ¿productora de culturas híbridas?”, en Actas del III Congreso Latinoamericano de la Asociación Internacional para el Estudio de la Música Popular.

www.hist.puc.cl/historia/iaspmla.html,,(consulta: octubre 2013).

García Piedra, J. C. (y J. C. Gil Siscar)

2007 "Lunares que entienden: Márgenes eróticos de la copla española clásica”, en Julián Acebrón, Rafael F. Mérida (eds.), Diàlegs gais, lesbians, queer / Diálogos gays, lesbianos, queer. Lleida, Universitat de Lleida.

Gómez Suarez, Águeda

2009 "El sistema sexo/género y la etnicidad: sexualidades digitales y analógicas", Revista Mexicana de Sociología, vol. 71, $n^{\circ} 4: 675-713$.

2013 “Tercer género y etnicidad en América Latina”, en J. Mª Valcuende y otros (coord.), Diversidad sexual en Iberoamérica. Sevilla, Aconcagua: 27-51. 
Grewal, Inderpal, (y Kaplan Caren)

1994 Transnational feminist practices and questions of postmodernity. In Scattered hegemonies: Postmodernity and transnational feminist practices. Minneapolis, University of Minnesota Press.

Guasch, Oscar

1991 La sociedad rosa. Barcelona, Anagrama.

1997 Observación participante. Madrid, Centro de Investigaciones Sociológicas.

2000 La crisis de la heterosexualidad. Barcelona, Laertes.

2011 "Social stereotypes and masculine homosexualities: The Spanish case", Sexualities, $n^{\circ} 14$ (5): 526543.

Hannerz, Ulf

1996 Conexiones transnacionales: cultura, gente, lugares. Madrid, Cátedra.

Herdt, Gilbert $\mathrm{H}$.

1996 Third sex, third gender: beyond sexual dimorphism in culture and history. New York, Zone Books.

Jackson, Peter A.

2000 "An Explosion of Thai Identities: Global Queering and Reimagining Queer Theory", Culture, Health and Sexuality, $\mathrm{n}^{\circ} 2$ (4): 405-424.

2001 "Pre-Gay, Post-Queer", Journal of Homosexuality, n 40/3: 1-25.

2009(a) "Global Queering and Global Queer Theory: Thai [Trans] genders and [Homo] sexualities in World History”, Autrepart, n 49: 15-30.

2009 (b) "Capitalism and Global Queering National Markets, Parallels Among Sexual Cultures, and Multiple Queer Modernities”, GLQ: A Journal of Lesbian and Gay Studies, vol. 15, n 3: 357-395.

Lancaster, Roger N.

1988 "Subject Honor and Object Shame: The Construction of Male Homosexuality and Stigma in Nicaragua", Ethnology, vol. 27, $\mathrm{n}^{\circ}$ 2: 111-125.

Llamas, R.

1998 Teoría torcida. Prejuicios y discursos en torno a la "homosexualidad". Madrid, Siglo XXI.

Manalansan Martin F.

1995 "In the Shadows of Stonewall: Examining Gay Transnational Politics and the Diasporic Dilemma", GLQ: A Journal of Lesbian and Gay Studies, $\mathrm{n}^{\circ} 2$ (4): 425-438.

Miano Borruso, Marinella

2002 Hombre, mujer y muxe en el Istmo de Tehuantepec. México, Plaza y Valdés.

Miano Barruso, M. (y A. Gómez Suarez)

2009 "Géneros, sexualidad y etnia vs globalización. El caso de los muxe entre los zapotecos del lstmo, Oax", XV Coloquio Internacional de Antropología Física Juan Comas. Mérida Yucatán.

http://webs.uvigo.es/etnicsexualidad/wp-content/uploads/2009/12/Ponencia Bahia Brasil.pdf,(consulta:

noviembre 2013).

Mira, Alberto

2004 De Sodoma a Chueca: historia cultural de la homosexualidad en España 1914-1990. BarcelonaMadrid, Egales.

Moreno, Isidoro

1972 Propiedad, clases sociales y hermandades en la Baja Andalucía. Madrid, Siglo XXI.

1974 Cofradías y hermandades andaluzas. Granada, Editoriales Andaluzas Unidas, 1985.

Murray, Stephen O.

1997 "Islamic Accommodations Male Homosexuality", en Stephen O. Murray, Will Roscoe (ed.), Culture, History, and Literature. New York, New York University Press: 14-54.

Murray, Stephen O. (y Will Roscoe) 
1997 "Introduction", en Stephen O. Murray y Will Roscoe (ed.), Islamic Homosexualities: Culture, History, and Literature. New York and London, New York University Press.

Nieto, José Antonio

2003 Antropología de la sexualidad y diversidad cultural. Madrid, Talasa.

Obermeyer, Carla Makhlouf

2000 "Sexuality in Morocco: Changing Context and Contested Domain", Culture, Health \& Sexuality, vol. 2, $\mathrm{n}^{\circ}$ 3: 239-254.

Ortiz, Renato

1994 Mundialización y cultura. Bogotá, Convenio Andrés Bello, 2004.

Parker, R.

1999 Beneath the Equator: Cultures of Desire, Male Homosexuality and Emerging Gay Communities in Brazil. New York, Routledge.

Peristiany, J. G.

1968 El concepto de honor en la sociedad mediterránea. Barcelona, Labor.

Pitt Rivers, J.

1979 Antropología del honor, o política de los sexos: ensayos de antropología mediterránea. Barcelona, Grijalbo.

Plummer, Ken

1991“La diversidad sexual: Una perspectiva sociológica”, en Manuel Delgado y otros, La sexualidad en la sociedad contemporánea. Lecturas Antropológicas. Madrid, Fundación Universidad Empresa.

1992 "Speaking its Name: Inventing a Lesbian and Gay Studies", en Ken Plummer (comp.), Modern Homosexualities. Fragments of Lesbian and Gay Experience. Nueva York, Routledge: 3-25.

Puar, Jasbir Kaur

2001 "Global circuits: Transnational sexualities and Trinidad", Signs, n² 26: 1039-1065.

2005 "Transversal Circuits: Transnational Sexualities and Trinidad", en Lise Nelson y Joni Seager, $A$ companion to Feminist Geography. Malden, Blackwell Publishing.

Rubin, Gayle

1984, "Reflexionando sobre el sexo: nota para una teoría radical de la sexualidad", en Carole Vance (comp.), Placer y peligro. Explorando la sexualidad femenina. Madrid, Editorial Revolución, 1989: 113-190.

Sabuco, A. (J. Ma Valcuende)

2003 “'La homosexualidad' como imagen hiperbólica de la masculinidad”, en J. Ma Valcuende y J. Blanco (orgs.), Hombres. La construcción cultural de las masculinidades. Madrid, Talasa: 135-155.

Tan, Michael L.

1995 "From Bakla to Gay. Shifting Gender Identities and Sexual Behaviors in the Philippines", en Richard G. Parker y J. Gagnon (ed.), Conceiving Sexuality. New York, Routledge: 85-96.

Triana, Fernando de

1935 Artes y artistas flamencos. Madrid, Editoriales Andaluzas Unidas, 1986.

Valcuende del Río, José María

2010. "Sexo entre hombres: los límites de la masculinidad", Revista Internacional de Ciencias Sociales y Humanidades (SOCIOTAM), vol. XX, nº 1: 11-37.

Villaamil, Fernando

2004 La transformación de la identidad gay en España. Madrid, La Catarata.

Vázquez García, Francisco (y Richard Cleminson)

2011 Los invisibles. Una historia de la homosexualidad masculina en España, 1850-1939. Granada, 
Comares.

Weeks, Jeffrey

2007 The World We Have Won: The Remaking of Erotic and Intimate Life. New York, Routledge.

Wikan, Unni

1977 "Man Becomes Woman: Transsexualism in Oman as a Key to Gender Roles", Man, New Series, vol. $12, n^{\circ} 2: 304-319$.

\section{Wright, Timothy}

2000 "Identity Politics in Bolivia La Nueva of the 1990s", The Journal of Latin American Anthropology, $\mathrm{n}^{\circ} 5$ (2): 89-111.

\section{Zito, Eugenio (Paolo Valerio)}

2010 Corpi sull'uscio, identità possibili. Il fenomeno dei femminielli a Napoli. Napoli, Filema.

2013 Genere: femminielli. Esplorazioni antropologiche e psicologiche. Napoli, Dante \& Descartes. 